\title{
Scientific Misconduct: From Salami Slicing to Data Fabrication
}

\author{
Stefania M. Mojon-Azzia Daniel S. Mojon ${ }^{a, b}$ \\ a Department of Ophthalmology, bScientific Secretary, Swiss Society of Ophthalmology, Kantonsspital St. Gallen, \\ St. Gallen, Switzerland
}

The aim of peer-reviewed biomedical journals is to publish accurate, new and relevant information on which researchers, medical doctors or the larger public can rely and build upon. Authors, reviewers and editors of such journals have responsibility for monitoring and maintaining high ethical standards and for trying to avoid any form of misconduct. This is not an easy task and several studies suggest that research results are not always conveyed accurately.

This problem is not new to science. Some illustrious scientists such as Galileo Galilei and Albert Einstein misrepresented their work in order to attain more convincing experimental results. Other famous scientists such as Claudius Ptolemy plagiarized the work of others. But it was only in 1981 that scientific misconduct came for the first time to public attention with the disclosure of four acts of misconduct occurring in the US [1]. Soon other cases appeared in several countries followed by the need to define misconduct and to develop guidelines and policies against it. Meanwhile many countries and large research institutions have introduced some type of scientific misconduct policy. However, too many countries and research organizations still lack such policies.

Definitions of scientific misconduct differ from country to country and from one institution or government agency to another. But independent of definition, scientific misconduct includes at least the fabrication (report- ing of experiments never performed), falsification (misrepresentation of results), and plagiarism (taking the writings or ideas of another and representing them as one's own) of data or ideas. Honest errors or honest differences in interpretation or judgments of data are excluded from most definitions of scientific misconduct [1]. Often also other serious deviations from accepted research practice are included like irresponsible authorship, duplicate publication, salami slicing, bias and conflict of interest and/or intentional erroneous use of statistical methods.

The incidence of scientific misconduct is difficult to determine and depends among other factors upon its definition. In comparison with the total number of individuals engaged in research the documented cases of scientific dishonesty are few in number. However, due to the difficulty of discovering and the reluctance of researchers to pursue cases of misconduct, the reported cases could only represent the tip of a large iceberg [2].

Even if the incidence of scientific misconduct might not be high, it is still high enough to warrant attention. One recent example from the US involved a former professor of ophthalmology at the Massachusetts Eye and Ear Infirmary and Harvard Medical School who admitted to having fabricated 21 chromatograms for a National Institute of Health grant application [3].

In order to prevent and fight such misconduct it is important to understand its causes. Reasons for scientific

\begin{tabular}{ll}
\hline KARGER & (c) 2004 S. Karger AG, Basel \\
Fax + 416130-3747/04/0361-0001\$21.00/0 \\
$\begin{array}{l}\text { E-Mail karger@karger.ch } \\
\text { www.karger.com }\end{array}$ & $\begin{array}{l}\text { Accessible online at: } \\
\text { www.karger.com/ore }\end{array}$
\end{tabular}

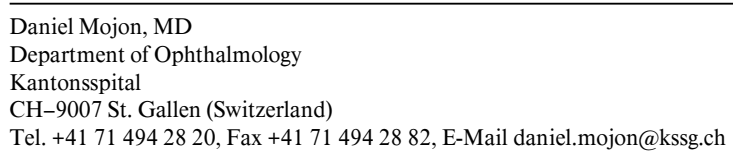




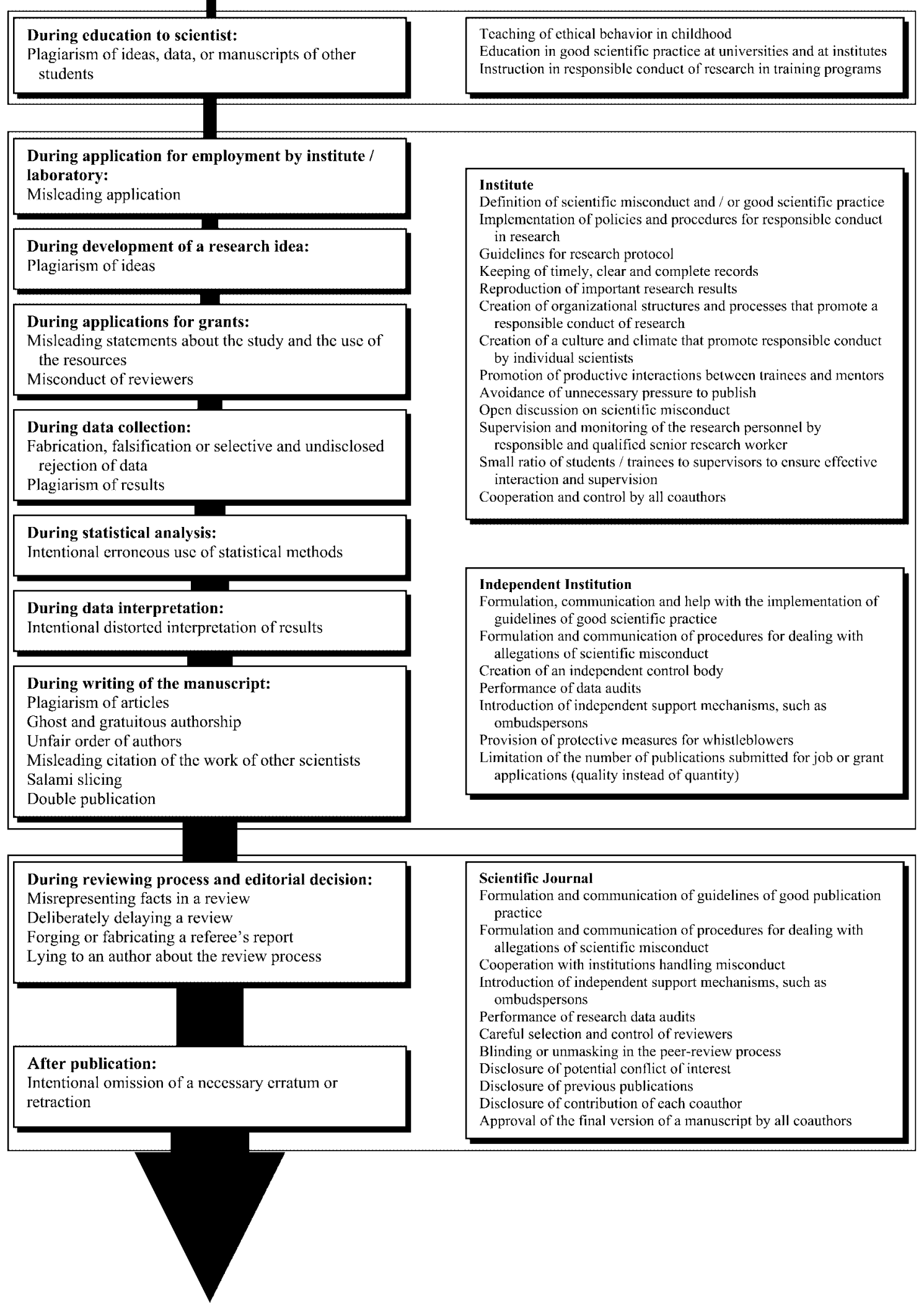

Fig. 1. Classification of scientific misconduct and selected measures against it. 
misconduct include career pressure, desire for peer recognition, necessity of publications for continuation or promotion of an academic appointment, monetary and professional rewards resulting from research output, deadlines, expectations and disappointment towards the produced results and lack of information in regard of ethical issues.

To secure scientific integrity two different lines should be followed: prevention and control [4]. Many of the measures implemented in several countries simultaneously achieve both goals. Measures against scientific dishonesty often include the definition of scientific misconduct and/ or good scientific practice, the publication of guidelines, the education of scientists in scientific ethics, the creation of independent organizations that deal with misconduct in science and are easily accessible for whistleblowers, researchers, editors and institutions, the supervision and monitoring of the research personnel by their research project leaders and the performance of data audits. Figure 1 summarizes the most important forms of scientific misconduct and presents selected measures against it.

The costs of acts of scientific misconduct are carried by the involved individuals and institutions as well as by the society as a whole in the form of ruined careers, lost reputation, long and expensive investigations, useless or even harmful diagnostic and therapeutic procedures, and the loss of public trust in science.
The goal of research must be to increase knowledge and to develop new ideas and understanding with important effects on all of society. Because of its crucial role, the importance of integrity in research cannot be overestimated. Today's research is only possible if scientists can build on the work of others and if the public trust in the integrity of scientists is maintained. Therefore, it is essential for maintaining scientific excellence and for keeping the public's trust to develop a culture that ensures that scientific publications are valid representations of the truth.

\footnotetext{
References $\quad 1$ Dooley JJ, Kerch HM: Evolving research misconduct policies and their significance for physical scientists. Sci Eng Ethics 2000;6:109121.

2 Steneck NH: Assessing the Integrity of Publicly Founded Research. A Background Report for the November 2000 ORI Research Conference on Research Integrity. http://ori.hhs.gov/multimedia/acrobat/backg int.pdf (accessed on August 13, 2003).

3 Office of Research Integrity: Findings on scientific misconduct. http://grants1.nih.gov/grants/ guide/notice-files/NOT-OD-01-006.html (accessed on August 13, 2003)

4 Riis P: Scientific dishonestry: European reflections. J Clin Pathol 2001;54:4-6.
} 